Conquest, Grants and Local Power:

Colonial Nobility ("nobreza da

terra") in Portuguese America and

Ancien Régime's Political Culture

\title{
Conquista, Mercês e Poder Local: \\ a nobreza da terra na América portuguesa e a cultura política do Antigo Regime.
}

Maria Fernanda Baptista Bicalho

Universidade Federal Fluminense

\section{Resumo}

Esse texto pretende, ao dialogar com o artigo "O 'Ethos' Nobiliárquico no final do Antigo Regime: poder simbólico, império e imaginário social", de Nuno Gonçalo Monteiro, pensar na formação das elites senhoriais da América portuguesa a partir de uma cultura política de Antigo Regime. Propõe-se a discutir a utilização do conceito de nobreza da terra na definição dessas elites, partindo do argumento de que a conquista ultramarina abriu um novo e alargado campo de possibilidades de prestação de serviços à monarquia e de remuneração dos mesmos pela coroa. Nesse sentido a formação da nobreza da terra no ultramar - numa sociedade escravista - teria se dado a partir da dinâmica de práticas e de instituições regidas pelo ideário da conquista, pelo sistema de mercês e pelo exercício do poder municipal.

\section{Abstract}

Considering Nuno Monteiro's essay, "Nobiliary 'Ethos' in the Dusk of the Ancien Régime: Symbolic Power, Empire and Social Imagery", and also the political culture of the Ancien Régime, this paper focuses on the formation of seignorial elites in Portuguese America. Taking into account that the conquest of the overseas' territories enlarged the prospects of acquiring revenue-earning commanderies and grants in exchange of services to the Crown, the author aims to debate the usefulness of the concept of colonial nobility (nobreza da terra) to define such elites. Thus, the formation of a colonial nobility in such territories - amongst a slave based society - would be the product of both practices and institutions guided by an ideal of conquest, a system of grants and the access to local power.

\section{Palavras-chave}

elites, Império português, Antigo Regime, câmaras municipais, história política.

\section{Keywords}

elites, Portuguese Empire, Ancien Régime, municipal councils, political history. 
Cf., entre outros, PRADO JÚNIOR, Caio. "O sentido da colonização". In: Formação do Brasil Contemporâneo. 15a edição. São Paulo: Editora Brasiliense, 1977, pp. 19-32; NOVAIS, Fernando. Portugal e Brasil na crise do antigo sistema colonial (1777-1808). São Paulo: Hucitec, 1979.

\section{2}

Entre os vários autores que analisam a importância e a centralidade da escravidão na constituição das elites coloniais, e defendem a especificidade da América portuguesa enquanto uma sociedade escravista colonial, cf. SCHWARTZ, Stuart. Segredos Internos. Engenhos e escravos na sociedade colonial. São Paulo: Companhia das Letras, 1995, especialmente capitulo 9: "Uma sociedade escravista colonial", pp. 209-223.

Cf. HESPANHA, António Manuel. As Vésperas do Leviathan. Instituições e Poder Politico. Portugal. Século XVII. Coimbra: Livraria Almedina, 1994, p. 278 e segs; XAVIER, Ângela B. e HESPANHA, António Manuel. "A Representação da Sociedade e do Poder". In: MATTOSO, José (dir.). História de Portugal. 0 Antigo Regime (1620-1807), vol. 4. Lisboa: Editorial Estampa, 1993, pp. 121156; OLIVAL, Fernanda. As Ordens Militares e o Estado Moderno. Honra, mercê e venalidade em Portugal (1641-1789). Lisboa: Estar Editora, 2001, pp. 15-38.

\section{4}

OLIVAL, op. cit., pp. 21-22. Sobre a economia de favores e os atos de dar, receber e retribuir - baseados em critérios de amizade, parentesco, fidelidade, honra e serviço - como elementos estruturantes dos modos de ver, pensar e agir ou seja, das relações sociais - no Antigo Regime ibérico, cf. XAVIER, Ângela B. e HESPANHA, António Manuel. "As Redes Clientelares". In: MATTOSO, op. cit., pp. 381-393.

5

HESPANHA, As Vésperas..., p. 496. Sobre as dinâmicas da expansão, os valores e as práticas que configuraram o império ultramarino português, cf. BETHENCOURT, Francisco e CHAUDHURI, História da Expansão Portuguesa, volumes 1 a 3. Lisboa: Círculo dos Leitores, 1998.

6

OLIVAL, op. cit., pp. 15 e 17. Sob uma outra chave interpretativa, analisando os benefícios que a monarquia portuguesa auferiu com o incremento mercantil através dos mares, graças às alfândegas, forjando "uma ordenação sistemática e completa do aparelho público em novos moldes - Estado burocrático e mercantilista", Vitorino Magalhães Godinho demonstra que em 1607, os gastos do reino, somente com tenças e moradias - pensões concedidas em troca de serviços prestados -, eram de 190 contos, quantia bem superior aos 167 contos arrecadados pelo Estado, na mesma época, no império atlântico. Cf. GODINHO, Vitorino Magalhães. "Finanças Públicas e Estrutura do Estado" In: Ensaios II. Lisboa: Sá da Costa, 1978, pp. 53 e 68-69.
0 comentário que se segue do texto " 0 'Ethos' Nobiliárquico no final do Antigo Regime: poder simbólico, império e imaginário social", de Nuno Gonçalo Monteiro, pretende refletir sobre a utilização do conceito de nobreza da terra na definição das elites coloniais - senhores de engenho e proprietários de terras e de escravos - numa sociedade que, para além de seu sentido comercial ${ }^{1}$ e de suas relações escravistas ${ }^{2}$, pautou-se em valores e práticas de Antigo Regime. Tais valores e práticas, no caso ibérico, derivam de uma visão corporativa da sociedade, difundida pelo paradigma jurisdicionalista dos séculos XVI e XVII, apontando para uma concepção limitada do poder régio, segundo a qual o monarca representava simbolicamente o corpo social e político, mantendo seu equilibrio e harmonia, zelando pela religião, preservando a paz e a ordem, garantindo, sobretudo, a justiça. Atributo mais importante da realeza, a justiça correspondia ao princípio de 'dar a cada um o que é seu', repartindo prêmio e castigo, respeitando direitos e privilégios, cumprindo contratos estabelecidos. ${ }^{3}$

\section{Cultura política de Antigo Regime no mundo ibérico}

Em seu livro As Ordens Militares e o Estado Moderno. Honra, mercê e venalidade em Portugal (1641-1789), Fernanda Olival nota que o desempenho de serviços era acompanhado da expectativa de prêmios que deveriam ser atribuídos de uma forma considerada justa. Nesse sentido, "a obrigação régia de dar devia ser feita de acordo com determinadas normas (...). A liberalidade não era assim espontânea; devia obedecer a preceitos para ser adequada e politicamente geradora do amor dos vassalos (...)".4

Se a expansão, desde o século XV, e a conquista do Novo Mundo, a partir do XVI, abriram um variado leque de possibilidades de prestação de serviços à monarquia, também agiram no sentido de ampliar o campo de ação da coroa, permitindo-Ihe dispor de novas terras, ofícios e cargos; atribuir direitos e privilégios a indivíduos e grupos; auferir rendimentos com base nos quais concedia tenças e mercês; além de criar uma nova simbologia do poder, remetendo ao domínio ultramarino da monarquia portuguesa. De acordo com António Manuel Hespanha, "com base na expansão, nos rendimentos que ela produzia, nas terras que ela abria a um enquadramento político e militar, nos empreendimentos organizativos e administrativos que ela possibilitava, a coroa podia produzir novas formas de remunerar e de organizar." ${ }^{5}$

Essas novas formas de remunerar e organizar estavam em plena consonância com as idéias e práticas de Antigo Regime. Fernanda Olival afirma que a "liberalidade, o gesto de dar era considerado, na cultura politica do Antigo Regime, como virtude própria dos reis, quer em Portugal, quer no resto da Europa Ocidental". Formulada desde Aristóteles, a liberalidade régia foi re-significada, enquanto valor, pela cultura cristã e pelos ideais de cavalaria medieval:

"Este pecúlio de idéias, aliado a outros referentes greco-latinos e do Cristianismo, sob diferentes apropriações, marcou as relações políticas dos homens do Antigo Regime, em tempos ditos de capitalismo comercial. Os reis deviam ter grandes riquezas, como advogavam muitos arbitristas de feição mercantilista de Seiscentos e de Setecentos, exatamente para poderem distribuir mais recursos e manterem mais servidores. Quantos mais fossem estes últimos, e mais ricos, maiores poderiam ser os domínios e os meios do Príncipe". 6 
7

A análise da formação da sociedade colonial - e do estabelecimento de relações entre centro (metrópole/ coroa/ rei) e periferias (conquistas/ conquistadores/vassalos ultramarinos) - a partir de um pacto baseado na cultura política do Antigo Regime, é a perspectiva que alguns historiadores vêm propondo em seus trabalhos. Cf. o conjunto dos capítulos do livro: FRAGOSO, João; BICALHO, M. Fernanda \&t GOUVÊA, M. Fátima (orgs.). 0 Antigo Regime nos Trópicos: A dinâmica imperial portuguesa (séculos XVIXVIII). Rio de Janeiro: Civilização Brasileira, 2001.

8

Cf., a respeito desse ponto, MONTEIRO, Nuno G. "Trajetórias sociais e governo das conquistas: Notas preliminares sobre os vice-reis e governadores do Brasil e da Índia nos séculos XVII e XVIII". In: FRAGOSO, BICALHO \& GOUVÊA (org.), O Antigo Regime..., op. cit., pp. 249-283.

OLIVAL, op. cit., p. 21.
0 imperativo do dar criava uma cadeia de obrigações recíprocas: disponibilidade para o serviço régio; pedido de mercês ao rei em retribuição aos serviços prestados; atribuição/ doação de mercês por parte do rei; engrandecimento / atribuição de status, honra e posição mais elevada na hierarquia social devido às mercês recebidas; agradecimento e profundo reconhecimento / reforço dos laços de submissão, lealdade e vassalagem; renovada disponibilidade de prestar mais e maiores serviços ao monarca. Tratava-se, como afirma Olival, de um verdadeiro círculo vicioso. Aquilo que a autora chama de "economia da mercê" tornou-se a base fundadora de uma cultura política de Antigo Regime - tanto na Europa, quanto nos trópicos. $^{7}$

Em seu texto, "0 'Ethos' Nobiliárquico no final do Antigo Regime: poder simbólico, império e imaginário social", Nuno Monteiro analisa o deslocamento sofrido pelo atributo de nobreza que, se nos primórdios da formação do Reino de Portugal identificava-se às funções exercidas, sobretudo militares - "os que combatem, os que detêm poderes jurisdicionais, os que recebem determinadas delegações da realeza" -, a partir do século $X V$, passou a ser mais uma 'qualidade', do que uma função. Por outro lado o autor destaca o papel absolutamente central da monarquia - do "monopólio régio das classificações sociais" - na hierarquização e regulação do espaço social nobiliárquico, por meio, sobretudo, da atribuição de benefícios materiais, honras e distinções - como a outorga de senhorios, de hábitos de comendas militares, de postos e ofícios na administração central e na própria casa real - em troca de serviços prestados e de vassalagem. Monteiro afirma, ainda, que tais sistemas e dispositivos - próprios das práticas e da cultura de Antigo Regime - foram, em parte, potencializados pelos "recursos, em fontes de rendimento e em oficios, fornecidos pela expansão colonial africana e asiática (e, mais tarde, brasileira)". E, a partir de então, afirma que, tanto no Reino, quanto no ultramar, a "possibilidade de prestar serviços relevantes era condicionada pelo acesso aos oficios que conferiam oportunidades para tal", e, entre os critérios de escolha para esses oficios contava cada vez mais a "qualidade de nascimento". ${ }^{8}$

Isso não descarta, no entanto, o fato de indivíduos provenientes de grupos sociais inferiores também terem sido sujeitos e objetos da "justiça distributiva" e da "mercê remuneratória", bases da mesma cultura, como afirma Olival:

"A justiça distributiva (...) era objecto de grande atenção na sociedade portuguesa do Antigo Regime. (...) Com efeito, servir a Coroa, com o objectivo de pedir em troca recompensas, tornara-se quase um modo de vida, para diferentes sectores do espaço social português. Era uma estratégia de sobrevivência material, mas também honorífica e de promoção. Como se verá, não terá sido apenas a primeira nobreza do reino que se adaptara a esta crescente dependência. Nos grupos sociais mais baixos, a questão fundamental era muitas vezes encontrar a disponibilidade necessária, nomeadamente econômica, para servir ".9

\section{A conquista ultramarina e a formação da nobreza da terra}

A conquista ultramarina abriu, sem dúvida, novo campo de possibilidades de prestação de serviços à monarquia e de remuneração dos mesmos pela Coroa. Se entre os critérios para a escolha daqueles aptos a prestar serviços mais relevantes no ultramar pesava consideravelmente a qualidade de nascimento, a conquista do Novo Mundo foi realizada por indivíduos em 
FRAGOSO, João. "A Nobreza da República: notas sobre a formação da primeira elite senhorial do Rio de Janeiro (séculos XVI e XVII) in Topoi. Revista de História, n. ${ }^{\circ}$. Rio de Janeiro: UFRJ, 2000, pp. 36-37; e FRAGOSO, João. "A Formação da economia colonial no Rio de Janeiro e de sua primeira elite senhorial (séculos XVI e XVII). In: FRAGOSO, BICALHO \&t GOUVÊA. O Antigo Regime..., op. cit, pp. 50-52.

\section{1}

Há historiadores que afirmam que a designação qualificada de nobreza da terra só pode ser usada ao nos referirmos à açucarocracia pernambucana. Alguns argumentam que, de toda a América portuguesa, só em Pernambuco colonial o termo nobreza da terra aparece na documentação. Dai ser ilegítima a utilização do termo no que concerne às demais capitanias da América portuguesa. 0 termo, no entanto, aparece em diferentes fontes de época. Só a título de exemplo, na carta $5^{\text {a }}$ das Cartas Chilenas, de autoria de Tomás António Gonzaga, lemos entre os versos 201 e 205: "Acaba-se a função e o nosso chefe / à casa, com o bispo se recolhe / A nobreza da terra os acompanha / Até que montam a dourada sege". (GONZAGA, Tomás Antônio. Cartas Chilenas. 2a edição. (Introdução e notas de Joaci Pereira Furtado). São Paulo: Companhia das Letras, 1996, p. 123. No entanto, o que se pretende aqui não é discutir se o termo encontra-se ou não na documentação, e sim a construção e legitimidade de utilização do conceito a partir de certos atributos das elites coloniais de diferentes capitanias.

\section{2}

MELLO, Evaldo Cabral de. Rubro Veio. 0 imaginário da restauração pernambucana. Rio de Janeiro: Topbooks, 1997, p. 153

13

Idem, p. 160

\section{4}

Id. Ibidem, p. 161-162. grande parte destituídos das mesmas qualidades. Em trabalhos recentes sobre o Rio de Janeiro nos séculos XVI e XVII, João Fragoso discute a formação de suas elites senhoriais, a partir da dinâmica de práticas e de instituições regidas pelo ideário da conquista, pelo sistema de mercês, pelo desempenho de cargos administrativos e pelo exercício do poder municipal. De acordo com o autor, cerca de $45 \%$ das famílias senhoriais - proprietárias de engenhos - do Rio de Janeiro no século XVII, tiveram origem em um oficial ou ministro régio. Tais famílias foram constituidas, em sua grande maioria, entre 1566 e 1620, em meio às lutas contra franceses e tamoios. Descendiam, portanto, de conquistadores dos tempos heróicos de fixação dos primeiros colonos na região. Alguns destes conquistadores vieram do norte de Portugal e das ilhas do Atlântico; outros, antes de chegarem ao Rio, passaram primeiro por São Vicente. Esses homens se transformaram, por intermédio dos serviços prestados ao rei na conquista e defesa do território, nos principais ou na nobreza da terra. ${ }^{10}$

Muito já se escreveu sobre o conceito de nobreza da terra e este é um tema polêmico para a historiografia brasileira que trabalha com o período colonial.11 Para discutir a "realidade social e institucional" dessa categoria nos trópicos é impossivel não mencionar os estudos de Evaldo Cabral de Mello. No capítulo intitulado "A metamorfose da açucarocracia", de Rubro Veio. 0 imaginário da restauração pernambucana, Mello afirma ter sido

"na segunda metade do século XVII que os descendentes dos restauradores passaram a reivindicar o estatuto de uma 'nobreza da terra', a ponto de, nos começos da centúria seguinte, os naturais de Pernambuco serem acusados de "se quererem quase todos inculcar por nobres".12

A metamorfose da açucarocracia em nobreza da terra é descrita pelo autor a partir de três manifestações conexas. A primeira consistiu no uso generalizado da expressão; a segunda, no aparecimento de um discurso e de uma prática genealógicos; e a terceira, no surgimento de "um dos mais caros topoi do imaginário nativista, o do caráter aristocrático da colonização Duartina".13

0 autor discute a substituição do termo principal - homens principais, os principais moradores, os principais de Pernambuco - pelo termo nobreza ou nobreza da terra. Em suas palavras, o termo principal "denotava riqueza, afluência, a posse de grandes cabedais". Era também aplicado

"ao individuo que detinha uma parcela do poder politico, seja por ocupar os cargos públicos da capitania e de pertencer [...] aos da 'governança desta terra', seja devido ao fato de dispor de uma clientela ou de um séqüito de homens livres e de escravos (o termo adjetivo 'principal' também era empregado para nomear os chefes indigenas), seja por tratar-se de religiosos ou de patentes militares, seja finalmente por ocupar uma posição proeminente".14

Com o fim da dominação holandesa, nobreza da terra tornou-se o novo coletivo adotado pelos descendentes dos antigos principais, uma vez que a açucarocracia pernambucana passou a apostar na promoção estamental como forma de legitimar sua dominação política, social e econômica da capitania. Nesse sentido, a auto-designação de

"'nobreza da terra' abrangia a dupla origem social da açucarocracia: a de 'nobreza do Reino' transplantada para Pernambuco; e a de nobreza gerada em Pernambuco durante o século e meio da sua colonização, 
Id. ibidem, p. 181-182. mediante a seleção social dos filhos e netos de individuos que, embora destituidos da condição de 'nobres do Reino', haviam participado das lutas contra os holandeses, ascendido à posição de senhores de engenho ou exercido cargos civis e militares, os chamados 'cargos honrados da República'."15

Não me deterei, aqui, no aparecimento de um discurso e de uma prática genealógicos a legitimar o status pretendido da nobreza da terra de Pernambuco; nem na questão do nativismo pernambucano, um dos temas mais caros ao autor. Só queria mencionar que, segundo Mello,

"o sentimento nativista tendeu previsivelmente a reforçar o critério de antiguidade em detrimento do da nobreza reinol, de modo que, ao longo do século XVIII, valorizar-se-á mais o fato de se descender de um colono duartino, de um herói das guerras holandesas, de um vereador de Olinda ou de um provedor da Santa Casa de Misericórdia do que de um morgado minhoto ou de um fidalgo da Casa Real. (...) A invocação dos serviços prestados na conquista da capitania, na sua restauração ou na sua governação, acrescentava-se agora o título adicional que consistia no fato de ser a 'nobreza da terra' o produto racial do cruzamento de troncos reinóis com mulheres indigenas".16

Porém, como acrescenta o autor, "desde que, por trás deles, opere, ao menos inicialmente, a fortuna familiar, a posse de 'grossos cabedais', mesmo quando encarnados na modéstia relativa que já era então, e provavelmente foi sempre, a da grande maioria de senhores de engenho". Isso porque,

"numa sociedade monocultora, escravocrata e latifundiária como a da mata do Nordeste, à propriedade açucareira é que correspondia, em última análise, a função de filtrar e de decantar, ao longo do tempo, as pretensões nobiliárquicas e as posições sociais".17

Portanto, para o historiador pernambucano a conquista de Pernambuco e sua posterior restauração do jugo holandês foram dois dos principais mecanismos de constituição da nobreza da terra naquela capitania. Também o fato de dispor de uma clientela ou de um séqüito de homens livres e escravos e o exercício de cargos na câmara atribuíram às famílias de senhores de engenho o estatuto de nobreza da terra. Esse estatuto, vivenciado não só em Pernambuco, mas em outras partes da América portuguesa, constituia-se em mais uma característica da cultura política de Antigo Regime, nos trópicos.

Também no Rio de Janeiro, creio que se possa falar da constituição de uma nobreza da terra baseada na conquista; e de sua interferência, por meio da câmara, no governo da res publica. A própria fundação da cidade foi resultado da conquista - ou reconquista da terra - das mãos dos franceses, aliados aos tamoios, a partir de 1560. Esta conquista foi protagonizada por homens provenientes de outras capitanias, como São Vicente, de Portugal e das ilhas atlânticas que, à custa de seu sangue e de suas fazendas, expulsaram os franceses, submeteram os índios e deram início ao estabelecimento luso na baía da Guanabara.

Fragoso se remete à participação, em 1560, dos Capitães-Mores de São Paulo Braz Cubas e Jorge Ferreira na conquista do Rio. Este último, num pedido de sesmaria, de 1573, declarava que "veio [ao Rio] por chamado do Governador Mem de Sá a tomar a fortaleza do Villegaignon 


\section{8}

FRAGOSO, João. "Knights, 'Archer Indians' and the Atlantic World. Rio de Janeiro in the 17th century". Trabalho apresentado no colóquio Imperial (Re)visions: Brazil and the Portuguese Seaborn Empire. Conference in Memory of Charles R. Boxer. Yale University, novembro de 2002, p. 7. Neste texto Fragoso relaciona os mesmos mecanismos, baseados no sistema de mercês, utilizados na conquista do Rio de Janeiro e na posterior conquista - ou re-conquista de Angola pelos fluminenses. Cf., também, a respeito, BOXER, C. R. Salvador de Sá e a luta pelo Brasil e Angola (1602-1686). São Paulo: Editora Nacional / Editora da USP, 1973; e ALENCASTRO, Luiz Felipe de. O Trato dos Viventes. A formação do Brasil no Atlântico Sul. São Paulo: Companhia das Letras, 2000.

\section{9}

Sobre a administração periférica da Coroa, cf. HESPANHA, As Vésperas..., op. cit., pp. 195-226.

\section{0}

FRAGOSO, "Knights...", op. cit., p. 9.

21

0 termo bandos encontra-se na documentação. Também no Estado da Índia essa terminologia era corrente. De acordo com S. Subrahmanyam, uma das explicações para que a comunidade dos casados não alcançasse convencer ao rei de nomear um dentre eles para o governo das capitanias nas quais residiam "era o facto de eles próprios se encontrarem muitas vezes profundamente divididos". Divisão que transparecia nos documentos e crônicas "como um problema de 'bandos"'. SUBRAHMANYAM, Sanjay. 0 Império Asiático Português (1500-1700). Lisboa: Difel, 1995, p. 320.

22

FRAGOSO, "Knights...", op. cit., p. 14.

23

FRAGOSO, João. "A nobreza vive em bandos: a economia política das melhores famílias da terra do Rio de Janeiro, século XVII. Algumas notas de pesquisa". In: Revista Tempo, vol. 8, n 15, julho - dezembro de 2003, pp. 30-32. aos franceses e tamoios com muita (...) gente e mantimentos; e armas com seus filhos e netos e cunhados, e parentes e amigos". Em 1575, seria a vez do Capitão-Mor de São Vicente, Jerônimo Leitão, chegar à Guanabara no comando de uma força militar paulista composta por 400 portugueses e 700 indios. Segundo o autor, esses homens aportaram na Guanabara não só com "suas pessoas", mas também com cabedais, parentes, criados, escravos e índios flecheiros. André de Leão declarava, em 1566, que fora ao Rio sob as ordens de Estácio de Sá, "em uma canoa sua, equipada de índios às suas custas". Em posterior pedido de sesmaria, Antônio de Mariz, antigo vereador em São Paulo, que também acompanhara Estácio de Sá, declarava o mesmo. Nesse sentido, a conquista do Rio de Janeiro contara com o apoio de moradores-vassalos de diferentes partes da América, das ilhas e do Reino que, ao disponibilizarem suas vidas e fazendas na guerra contra índios e franceses, esperavam do rei, em troca, reconhecimento e mercês: em terras, comendas, cargos, ofícios e privilégios:

Em realidade, a maneira pela qual o Rio de Janeiro fora conquistado deu margem a fenômenos que esclarecem alguns dos traços da sociedade colonial da região e de sua elite: a formação de redes politicas entre segmentos das elites regionais; a constituição de uma nobreza da terra baseada na conquista; e a sua interferência no governo da cidade (...).18

Expulsos os franceses e submetidos os índios, cabia, segundo Fragoso, aos que participaram da conquista, a organização político-administrativa da área recém-incorporada ao domínio luso. Como afirmava Frei Vicente do Salvador, "fundada pois a cidade pelo Governador Mem de Sá (...), ordenou logo que houvesse nela oficiais e ministro da milícia, justiça e fazenda". Antônio de Mariz, já em 1570, participava da câmara fluminense e, anos depois, ocupava o posto de provedor da Fazenda Real. Este, assim como tantos outros exemplos demonstram a circulação dos mesmos homens por duas esferas diferentes de poder: a câmara e a administração periférica da Coroa. ${ }^{19}$ Fragoso relaciona, entre 1565 e 1620, cerca de 107 oficiais da câmara, dos quais pelo menos 62 , ou seja, $58 \%$, ocuparam também cargos na administração periférica, exercendo postos-chave na gestão da nova sociedade - o que era facilitado pelas alianças, inclusive por meio de casamentos, entre as famílias que acabariam se constituindo nas melhores familias da terra, ou seja, na nobreza da terra. 20

No entanto, o autor nos alerta, ainda, para as reciprocidades entre esses homens, suas famílias e seus bandos ${ }^{21}$, e as populações indígenas:

"Para este assunto, basta lembrar que, a exemplo de São Paulo e de Pernambuco, algumas das melhores familias do Rio casaram seus rebentos com descendentes de 'principais' indígenas. Este fora o caso de Gonçalo Correia de Sá, filho do Governador do Rio, Salvador Correia de Sá. Ou ainda de um do Capitão Gaspar Vaz, que esposou a filha de Araribóia, um dos principais lideres indigenas aliados dos lusos na conquista do Rio. (...) Por meio destas negociações, conseguiam-se, entre outras coisas, flecheiros e, com isto, os fidalgos dos trópicos ampliavam suas bases guerreiras."22

Mas não só as alianças com os indígenas contribuíram para consolidar o poder social da nobreza da terra, segundo o autor. 0 crescimento da economia baseada na escravidão africana acarretaria, igualmente, a multiplicação de reciprocidades com os cativos da Guiné. ${ }^{23}$ Evidentemente, tais negociações ocorriam em meio a conflitos entre senhores e escravos, 
24

Idem, p 32.

25

SCHWARTZ, Stuart. Segredos Internos. Engenhos e escravos na sociedade colonial. São Paulo: Companhia das Letras, 1988, pp. 234235.

26

Idem, p. 235. a revoltas escravas, à formação de quilombos e à repressão dos mesmos. No entanto, os escravos também participavam nas lutas entre bandos da nobreza da terra. Em 1691, o reitor do colégio dos jesuitas escrevia a Lisboa sobre os ataques às fazendas da Companhia de Jesus, em Campos, pelos negros de José Barcelos e de Martim Correia Vasqueanes:

"(...) armados com flechas, dardos e armas de fogo foram a um dos currais (...) investindo aos tiros [os] negros que (...) nele [viviam], matarão dois (...) deixando muitos feridos e todos molestados (...). Ameaçando os que [voltassem] aquele sitio os haviam de matar e ainda não satisfeitos queimaram as casas e derrubaram o dito curral". 24

Escravos armados, fazendas invadidas e danificadas, e seus cativos feridos. Este não é um quadro exclusivo do Rio de Janeiro de finais do século XVII. Afirmando ter sido um "acontecimento extraordinário", embora "revelador da dinâmica social do Recôncavo" da Bahia, Stuart Schwartz nos conta sobre uma contenda ocorrida em novembro de 1717, entre um escravo do engenho Sergipe e um capitão-do-mato mulato, que acabou envolvendo não apenas o administrador do mesmo engenho, padre Luís Veloso, mas outros "230 individuos, inclusive os mais ilustres senhores de engenho do Recôncavo". Encontrando-se em Santo Amaro, o escravo foi interpelado por João Dornelas, capitão do mato, que estava bêbado:

"Discutiram, e um dos insultos proferidos pôs em dúvida a virilidade do senhor jesuita daquele cativo. Este reagiu, e foi apunhalado e espancado. Dornelas aprisionou-o como fugitivo e colocou-o em um barco para leva-lo a Salvador. Ao saber do ocorrido, o padre Luís Veloso (...) enviou alguns escravos armados, em canoas, para interceptar o capitão do mato. Houve luta, Dornelas foi gravemente ferido e morreu nas docas do engenho".25

0 ocorrido foi comunicado a Salvador e o governador, marquês de Angeja, enviou soldados para prenderem os escravos culpados, que, no entanto, fugiram, assim como todos os empregados livres do Engenho Sergipe. Este foi mantido em "estado de sítio" por quase três semanas. A argumentação de Schwartz é a de que a autoridade da Coroa estava sendo posta à prova, e o próprio marquês de Angeja escrevera a Portugal afirmando que "Veloso agira ditatorialmente, e que fora poderoso o suficiente para controlar o Recôncavo e suprimir a verdade". No entanto, Veloso conseguira angariar a assinatura de 230 homens, "inclusive os mais ilustres senhores de engenho do Recôncavo", atestando suas virtudes. ${ }^{26}$ Tal fato demonstra que atitudes como a do padre-administrador de engenho não eram tão inusitadas aos olhos dos seus pares. Demonstra também que a utilização de escravos armados por seus senhores na resolução de diferentes querelas não devia ser um fato tão extraordinário assim.

Portanto, alianças com seus pares e negociação com outros estratos sociais eram duas estratégias da nobreza da terra na manutenção de seu poder, ao menos no âmbito local.

\section{A nobreza da terra, a administração da res publica e o governo do Império}

Um outro ponto destacado por Nuno Monteiro, em seu texto, é que na prática social e institucional portuguesa a categoria 'nobre' assumiu uma conotação excepcionalmente ampla - distinta da de 'fidalgo', noção mais restrita - incluindo uma multiplicidade de oficios e funções, diversas das 
27

Cf. MONTEIRO, Nuno Gonçalo. "Poder senhorial, estatuto nobiliárquico e aristocracia". In: MATTOSO, op. cit., pp. 334-335; e 0 Crepúsculo dos Grandes. A casa e o patrimônio da aristocracia em Portugal (1750-1832). Lisboa: Imprensa Nacional Casa da Moeda, 1998, pp. 22-23.

\section{8}

MONTEIRO, Nuno Gonçalo. "Elites locais e mobilidade social em Portugal nos finais do Antigo Regime". In: Análise Social, n 141. Lisboa: Instituto de Ciências Sociais, 1997, p. 356.

29

MAGALHÃES, Joaquim Romero. O Algarve econômico (1600-1733). Lisboa: Editorial Estampa, 1988, pp. 348 e 334 .

30

MAGALHÃES, Joaquim R. "Os nobres da governança das terras". In: MONTEIRO, Nuno G. F; CARDIM, Pedro \& CUNHA, Mafalda S. Da (orgs). Optma Pars. Elites Ibero-Americanas do Antigo Regime. Lisboa: Imprensa de Ciências Sociais, 2005, p. 67. tradicionais. Em trabalhos anteriores Nuno Monteiro afirma que diante do progressivo alargamento dos estratos terciários urbanos e da correspondente ampliação do conceito de nobreza, corria-se o risco de uma total banalização e descaracterização deste estado, ao mesmo tempo em que se reforçava a estrutura hierárquica e nobiliárquica da sociedade. Nesse sentido, para atribuir um estatuto diferenciado aos titulares destas novas funções sociais, a doutrina jurídica criou, ao lado dos estados tradicionais, um "estado intermédio" ou "estado privilegiado" eqüidistante entre a antiga nobreza e o povo mecânico. Forjava-se assim o conceito de "nobreza civil ou politica", abarcando aqueles que, embora de nascimento humilde, conquistaram um grau de enobrecimento devido a ações valorosas que obraram ou a cargos honrados que ocuparam, mormente os postos da república, diferenciando-se, portanto, da verdadeira nobreza derivada do sangue e herdada dos avós. Conclui que este novo conceito, já largamente incorporado à literatura jurídica do século XVII, acabaria por se impor na prática de muitas instituições portuguesas do Antigo Regime, "contribuindo não apenas para a distinção entre nobreza e fidalguia (mais restrita), mas ainda para a efetiva 'banalização' das fronteiras da nobreza portuguesa, tornadas das mais difusas da Europa". 27

No que diz respeito às elites locais, chamando a atenção para a diversidade da base de recrutamento das "oligarquias municipais", o autor defende que, em Portugal, a "nobreza institucional" que compunha os cargos de governança dos concelhos não correspondia necessariamente aos indivíduos considerados nobres no plano do direito; sendo que nas pequenas localidades podia haver "pessoas mecânicas" com assento nas vereações. Conclui que "não era o estatuto geral delimitado pela legislação, mas sim os 'usos' de cada terra e as relações de força no terreno que definiam o limiar de acesso às nobrezas camarárias".28

Da mesma forma, Joaquim Romero Magalhães considera a nobreza constitutiva das câmaras municipais portuguesas, "uma classe social formada dentro da ordem ou estado popular e que, pela sua conduta, modo de vida e exercício do governo concelhio, conseguiu ficar nas bordas da ordem da nobreza". A seu ver, estes nobres, também denominados cidadãos, assumiam alguns valores, alguns padrões de conduta, e o viver ao estilo da nobreza. Sentiam e se comportavam como a aristocracia ao considerarem degradante o manejo do dinheiro, ao presumirem-se honrados em participar do governo municipal, ao poderem - em decorrência disto - alardear pureza de sangue, prestígio, reconhecimento público, insígnias, precedências e aparato no exercício de suas funções. ${ }^{29}$

Em recente capitulo, "Os nobres da governança das terras", do livro Optma Pars. Elites Ibero-Americanas do Antigo Regime, Romero Magalhães volta a afirmar que,

"Pertencer à gente nobre da governança das terras implicava constar dessas pautas dos elegíveis para a vereação, ser inscrito no 'rol da nobreza' ou 'arruamento da nobreza'. Essa gente nobre da governança das terras continua a não se confundir com a fidalguia que Ihe fica acima, nem com os cidadãos que ocupam lugares mais baixos nas câmaras, nomeadamente os lugares de procurador ou de tesoureiro do concelho. Mas é do grupo dos cidadãos que é originária, embora dele consiga destacar-se. E tudo fará para que essa nobilitação semântica corresponda a uma realidade social concreta. Distinção pelos lugares ocupados, pelos ofícios desempenhados, pelas alianças familiares, sobretudo pelo modo de vida 'à lei da nobreza'". 30 
MONTEIRO, "Elites locais e mobilidade..., op. cit. p. 344.

32

Cf, a esse respeito, BOXER, C. R. Portuguese Society in the Tropics. The Municipal Councils of Goa, Macao, Bahia, and Luanda (15101800). Madison and Milwaukee: The University of Wisconsin Press, 1965; e, do mesmo autor, "Conselheiros Municipais e Irmãos de Caridade". In: O Império Colonial Português (1415-1825). Lisboa: Edições 70, 1981

\section{3}

BICALHO, Maria Fernanda B. "Centro e Periferia: pacto e negociação política na administração do Brasil colonial". In: Leituras. Revista da Biblioteca Nacional, n. ${ }^{\circ}$ 6. Lisboa: primavera 2000, pp. 17-39; e "As câmaras ultramarinas e o governo do Império", In: FRAGOSO; BICALHO \& GOUVÊA, O Antigo Regime..., op. cit., pp. 189221

\section{4}

BICALHO, Maria Fernanda B. "O que significava ser cidadão nos tempos coloniais". In: ABREU, Martha \& SOIHET, Rachel. Ensino de História. Conceitos, temáticas e metodologia. Rio de Janeiro: Casa da Palavra / Faperj, 2003, pp. 139151. Os cidadãos eram os responsáveis pela res publica, ou seja, pelo governo da comunidade. Cidadãos eram, em suma, aqueles que, por eleição de seus pares, desempenhavam ou haviam desempenhado cargos administrativos nas câmaras, bem como seus descendentes. Cf. GODINHO, op. cit., pp. 46-47. De acordo com Francisco Ribeiro da Silva, a qualidade de cidadão podia ser adquirida: 1) pelo nascimento, de acordo com a expressão bastante corrente "filhos e netos de cidadãos"; 2) pelo merecimento, cabendo ao rei, a quem competia distribuir mercês, títulos e privilégios, arbitrar sobre a sua concessão; 3 ) por via institucional, por meio do exercício de certas funções no governo das localidades; 4) pelo matrimônio com filhas de cidadãos; 5) e, finalmente, pelas letras; a condição de letrado constituindo-se em mérito para se ascender na escala social. SILVA, Francisco $R$. da - O Porto e seu Termo (1580-1640), vol. 1. Porto: Arquivo Histórico / Câmara Municipal do Porto, 1988, pp. 296-301.
No entanto, como afirma Nuno Monteiro, o acesso aos ofícios da governança - por depender dos contextos locais e por conferir um prestígio variável - não constituiu o canal privilegiado para o reconhecimento da nobreza. Afirma que, "ao contrário dos hábitos de cavaleiro das ordens militares, que em todo o reino tinham as mesmas condições de acesso e conferiam um idêntico estatuto, a ascensão à governança de uma terra tinha uma eficácia sobretudo local". 31

Se o acesso aos ofícios da governança não representou um mecanismo privilegiado para o reconhecimento da nobreza em Portugal, creio que o mesmo não pode ser dito em relação à constituição de uma nobreza da terra nas conquistas. Se foram raros os naturais da colônia que se aproximaram do centro de decisão política da Coroa; se a obtenção de distinções superiores da monarquia foi praticamente vedada às elites coloniais; se a clivagem que no território peninsular se verificou entre as elites da corte e as das províncias foi acentuada não somente pela distância entre colônias e metrópole, mas e principalmente pelo fato de serem colônias; se os governos das capitanias fugiram progressivamente ao alcance dos que se viam como conquistadores, restava-Ihes a câmara como lugar e veículo de nobilitação, de obtenção de privilégios e, sobretudo, de negociação com o centro - com a Coroa - no desempenho do governo político do Império. ${ }^{32}$

Em outras palavras, no ultramar, o acesso aos cargos camarários surgia como objeto de disputas entre grupos economicamente influentes nas localidades. Estas disputas podem ser entendidas como um dos fatores que indicam a centralidade daqueles cargos não apenas enquanto espaço de distinção e de hierarquização das elites coloniais, mas e principalmente, de negociação com a Coroa. ${ }^{33}$ Isso porque as câmaras constituiram-se em uma das principais vias de acesso a um conjunto de privilégios que permitia nobilitar os colonos, transformando-os em cidadãos. ${ }^{34}$

Por sua fidelidade e por terem se destacado no ato de servir ao rei, os cidadãos de algumas cidades portuguesas receberam, em troca, honras, liberdades e privilégios. É o caso de Lisboa, de Évora e do Porto. Tomando como exemplo esta última, D. João II justificaria a concessão de tal graça, em 1490, devido aos serviços que os reis de Portugal, seus antepassados, receberam "da mui nobre e leal Cidade do Porto e cidadãos dela", como demonstrações de lealdade e de fidelidade.

Em 1642, dois anos após a Restauração e aclamação de D. João IV, os cidadãos da cidade de São Sebastião do Rio de Janeiro recebiam os mesmos privilégios, honras e liberdades conferidos, em 1490, à cidade do Porto. Em 1646 seria a vez dos cidadãos de São Salvador da Bahia de Todos os Santos serem agraciados com os mesmos privilégios. Os vereadores de São Paulo de Luanda, em Angola, receberam-nos em 1662, em reconhecimento dos sofrimentos passados durante a ocupação holandesa. Sem dúvida, todos aqueles colonos destacaram-se na fidelidade à Casa de Bragança.

Mais uma vez, a exclusividade de doação de títulos e mercês atribuia ao monarca o monopólio de graduar e de qualificar por seu próprio arbítrio, regulando e hierarquizando as ordens, os estamentos, as linhagens e os bandos, tanto em Portugal quanto no Brasil. No sentido inverso, a competitividade dos súditos em torno deste tipo de privilégio numa sociedade que se moldava à cultura política de Antigo Regime - e, no caso do Brasil, numa sociedade que, para além disso, também era escravista -, ou seja, as disputas pela inclusão no círculo dos credenciados a exercer as funções e os cargos não apenas no governo municipal, mas ainda nos ofícios periféricos 
35

FRAGOSO, João; GOUVÊA, Maria de Fátima S. \& BICALHO, Maria Fernanda B. "Uma Leitura do Brasil Colonial. Bases da materialidade e da governabilidade no Império" in Penélope. Revista de História e de Ciências Sociais, n. 23. Lisboa: Novembro de 2000, pp. 67-88.

36

Cf. PUNTONI, Pedro. A guerra dos Bárbaros. Povos indigenas e a colonização do sertão nordeste do Brasil 1650-1720. São Paulo: Hucitec, 2002. da monarquia - como a Provedoria da Fazenda Real, uma conezia vacante, ou a capitania de uma fortaleza - evidenciavam e legitimavam, como nos mostra Nuno Monteiro, o monopólio da Coroa enquanto instância de estruturação social e institucional, não apenas no Reino, mas igualmente nos domínios ultramarinos.

Portanto, a categoria de "principais da terra" ou "homens principais", como se auto-denominavam, ou ainda, o conceito de "nobreza da terra" aplicado às conquistas, ligava-se não apenas às qualidades inatas, como a ascendência familiar ou a pureza de sangue, ou à posição adquirida por via econômica ou política, como o ser senhor de terras e de escravos, e o ter acesso à câmara. Incorporava também os méritos da conquista, povoamento e defesa da colônia. Em cidades como Olinda, Salvador ou Rio de Janeiro as pessoas que se arrogavam o título de "principais" ou de "nobreza da terra", justificavam-no não enquanto uma categoria natural ou jurídica, de acordo com o direito do Antigo Regime, mas por meio de um discurso - baseado numa cultura política - que valorizava sua condição de protagonistas na conquista ultramarina.

0 que nos leva a concluir que o ideário da conquista, a "economia da mercê" e o exercício do poder camarário apareciam, na dinâmica do Império português, como mecanismos de afirmação do vínculo político entre vassalos ultramarinos e soberano. A eficácia da ação da nobreza da terra nas conquistas pode ser, portanto, pensada não apenas no âmbito local, uma vez que ela se constituiu no principal agente de interlocução entre os interesses locais e o poder central. Ao tecer cadeias de negociação e redes pessoais e institucionais de poder e de patrocínio, a condição de nobreza da terra nas conquistas viabilizou o acesso dos "descendentes dos primeiros conquistadores" e dos "homens principais" a cargos administrativos e a um estatuto político - como o ser cidadão - hierarquizando os indivíduos, assim como os serviços prestados por eles, em espirais de status e de poder que garantiam - a partir de importantes localidades, como o Rio de Janeiro, Salvador e Olinda - a coesão política e o governo do Império. ${ }^{35}$

\section{Guerra viva, pacto e coesão do Império}

Recuperando o ethos da nobreza em Portugal, Nuno Monteiro afirma que ao longo do Antigo Regime, apesar da "proclamada equiparação ou preferência das letras às armas, estas nunca deixaram de ser privilegiadas nos imaginários nobiliárquicos". Até 1765, segundo o autor, os serviços prestados no norte da África constituíram-se na "via decisiva para se receber mercê de um hábito de cavaleiro de uma ordem militar", o que o leva a concluir que "os serviços feitos na 'guerra viva' nunca tiveram equivalente".

Considera, no entanto, problemático estender o conceito de 'guerra viva' ao Brasil, sobretudo no século XVII, na medida em que as "'guerras dos bárbaros' na América não podiam ter o mesmo estatuto remuneratório que os feitos bélicos que se travavam em outras paragens" 36 . Por outro lado, relaciona as representações dominantes e as tabelas de remuneração dos serviços com os "momentos fundadores", nos quais o Norte de África e a Índia nunca deixaram de ter o seu peso, mesmo quando, a partir da segunda metade dos seiscentos, sua importância econômica diminuiu frente ao protagonismo que o Brasil foi assumindo na dinâmica do Império português.

Ao defender a importância dos serviços militares para a primeira nobreza do Reino, sobretudo após a Restauração de 1640, Nuno Monteiro toca, a meu ver, num ponto essencial para se compreender não só a monar- 
37

MELLO, Rubro Veio..., op. cit., pp. 105-152.

38

Idem, p. 127. Em outro momento, retomando a questão, o mesmo autor afirma que "essa noção contratualista nada tinha de novidade teórica nem de conteúdo revolucionário, prendendose às já então arcaicas concepções constitucionais do escolasticismo tardio". Cf. MELLO, E. C. de. A Fronda dos Mazombos. Nobres contra Mascates. Pernambuco (1666-1715). São Paulo: Companhia das Letras, 1995, p. 139.

39

Cf., sobre a noção de pacto, BICALHO, Maria Fernanda B. "Centro e Periferia: pacto e negociação política na administração do Brasil colonial". In: Leituras. Revista da Biblioteca Nacional, n. ${ }^{\circ}$, primavera 2000, pp. 17-40. quia restaurada sob a Casa de Bragança, mas ainda o pacto que deu coesão ao Império ultramarino, pacto efetuado entre a Coroa e os conquistadoresrestauradores do além-mar - transformados em nobreza da terra pelo sistema de mercês e pelo desempenho de cargos concelhios - e sustentado pela cultura política de Antigo Regime. Nos termos do autor,

"o facto de terem [as casas nobres do Reino] sustentado a dinastia de armas na mão nos seus momentos fundacionais constituía parte integrante e fundamental do pacto que julgavam ter estabelecido com a monarquia e que esta reconhecia como fundamento para a perpetuação do seu estatuto, contra ventos e marés. (...) Mais exactamente, essas obrigações eram assumidas como dimensões "constitucionais" do regime brigantino, como um pacto tácito (e algumas vezes explicito), quase invariavelmente aceite pelas instituições da monarquia, entre a dinastia e as casas aristocráticas que na guerra a tinham defendido e sustentado".

0 autor delimita, portanto, três questões, a seu ver fundamentais, na configuração das principais Casas da nobreza lusitana: 1) a sustentação e a defesa da monarquia pelas armas, na guerra viva; 2) o caráter fundador dessas ações; 3) a dimensão constitucional do regime brigantino, baseado num pacto entre a nobreza e a monarquia.

Encontramos essas três dimensões, num outro patamar, também na América. Comecemos pela terceira, ou seja, a dimensão constitucional e pactícia da monarquia portuguesa pós-restauração. No capítulo "À custa de nosso sangue, vidas e fazendas", de Rubro Veio. 0 imaginário da restauração pernambucana, Evaldo Cabral Mello analisa as representações encaminhadas ao rei pelos vassalos de Pernambuco, pedindo-Ihe honras, mercês e cargos em troca de seu empenho na conquista da capitania e na sua restauração e expulsão dos holandeses. ${ }^{37} 0$ imaginário político que deu corpo a esse discurso fundava-se, segundo o autor, numa concepção contratual ou pactícia que não era estranha à teoria do direito ibérico no Antigo Regime:

"da restauração [de Pernambuco e expulsão dos holandeses] alcançada 'à custa de nosso sangue, vidas e fazendas', tirava-se o corolário da existência de um pacto entre a Coroa e a 'nobreza da terra', o qual teria estabelecido em favor desta um tratamento preferencial, um estatuto juridico privilegiado, um espaço de franquias, que a pusera ao abrigo das inferências reinóis, legitimando sua hegemonia sobre os demais estratos sociais da capitania, em especial, sobre o comércio português nela estabelecido".38

Em contrapartida a demonstrações de empenho e vassalagem na manutenção e na defesa dos territórios ultramarinos, os naturais de Pernambuco reivindicavam para si uma série de distinções e um acesso privilegiado ao governo das conquistas. Ao retribuir os feitos de seus vassalos, a Coroa reafirmava o pacto político que os unia a si própria. A partir desses valores, noções e práticas do Antigo Regime - e que tinham na economia das mercês sua lógica fundadora - os conquistadores da América portuguesa dispunham suas vidas e fazendas em prol de uma causa que não era apenas sua ou dos grupos que representavam; tornandose, enquanto vassalos do Rei de Portugal, agentes da fundação e da coesão do Império português. ${ }^{39}$

Voltando à primeira assertiva de Nuno Monteiro, talvez a guerra dos bárbaros, no Brasil, ou a guerra de Ambuila, em Angola não tenham tido 
40

Arquivo Histórico Ultramarino, documentos avulsos do Rio de Janeiro, caixa 4, docs. 105 e 106

41

MELLO, Rubro Veio..., op. cit., p. 127. propriamente uma dimensão, quer fundadora, quer pactícia. Mas, sem dúvida a conquista da América, embora de forma menos heróica - ou cavalheiresca - do que a do norte da África e a da İndia, também teve seu caráter fundador, de sustentação e defesa da monarquia - e do Império - e de pacto entre conquistadores e Coroa.

Exemplo disso é a solicitação feita a D. Pedro pelos oficiais da câmara do Rio de Janeiro, pedindo-Ihe que os "moradores naturais do Estado do Brasil, sendo idôneos" fossem preferidos aos reinóis nos postos de guerra, oficios, conezias e dignidades que vagassem naquele Estado. Argumentavam que

"nossos pais e avós naturais, que foram desse Reino, Vossa Alteza os mandou em seu serviço à povoação deste Estado, depois de o conquistarmos, de justiça deve Vossa Alteza preferir para o servirmos em os lugares dele, e este maior merecimento não deve ser a causa de nossa pena, nem estorvo para deixarmos de mandar a nossos filhos com tantos riscos, e dispêndios a servirem a V. A. nesse Reino, e neste Estado, como vassalos naturais de V. A."

De acordo com o parecer do Conselho Ultramarino,

"em quarenta anos de guerra continuada padeceram os ditos moradores muitas misérias, e infinitas hostilidades na defesa daquele Estado, aonde a maior parte deles se assinalaram (sic) em muitas ocasiões com singular valor, e com grande despesa de suas fazendas, com que a este respeito deve V.M. ser servido mandar que nos postos de milícia que vagarem no dito Estado, sejam somente providos os que nele têm servido a V.M., e da mesma maneira nos ditos moradores os ofícios de justiça e fazenda, como também em seus filhos as igrejas, conezias e dignidades, pois é justo que despendendo seus avós e seus pais as fazendas, derramando seu sangue, e perdendo muitos as vidas sejam os postos, os cargos, e honras do dito Estado concedidas a estes sujeitos em que concorrerem as partes e qualidades necessárias".

0 despacho régio confirma que o rei mandará advertir ao Conselho Ultramarino e à Mesa de Consciência e Ordens, "o que me pedis, que me parece justo".40

Como afirma Evaldo Cabral de Mello, enquanto os pernambucanos se consideravam vassalos mais políticos do que naturais do rei de Portugal - "por haverem restaurado seus pais e avós aquele Estado da tirânica potência de Holanda" - os habitantes do Reino, assim como os demais povoadores - e conquistadores - da América, deviam à Coroa uma "vassalagem natural". 41

E então, caberia a pergunta: a restauração pernambucana não poderia ser considerada uma modalidade de guerra viva? Embora protagonizada, não pela primeira nobreza do Reino, e sim pela nobreza da terra de Pernambuco, não possuiria - guardada as proporções - ingredientes fundacionais e pactícios semelhantes e contemporâneos aos da Restauração portuguesa? Certamente - e não há como discordar - que a primeira nobreza sustenta a dinastia. Mas não poderíamos dizer que os conquistadores, transformados em "nobreza da terra" - como já se discutiu acima - possuem um papel importante na fundação, na sustentação, na coesão e no acrescentamento do Império, pelo menos no que diz respeito à sua porção no Atlântico-Sul? A reconquista de Angola aos holandeses, em 1648, 
42

GODINHO, op. cit., p. 53.

43

OLIVAL, op. cit., pp. 15-17.

44

Luiz Felipe de Alencastro argumenta que 0 movimento de Restauração portuguesa levou à separação que entre dois agentes sociais distintos, o homem ultramarino e o homem colonial: "O primeiro faz sua carreira no ultramar buscando lucros, recompensas e títulos desfrutáveis na corte. 0 segundo circula em diversas regiões do Império, mas joga todas as suas fichas na promoção social e econômica acumulada numa determinada praça, num enclave colônia (...)". ALENCASTRO, op. cit., p. 103. por homens, forças e cabedais arregimentados no Rio de Janeiro - além de seus criados e índios flecheiros - não foi também uma espécie de guerra viva que restaurou a integridade e a coesão do Império?

E o que seria da dinastia sem o Império? Não eram as alfândegas que, segundo Magalhães Godinho, sustentavam a monarquia?42 $\mathrm{Ou}$, dito de outra forma, não foram os "tempos ditos de capitalismo comercial" que, segundo Fernanda Olival, permitiram o pleno desenvolvimento da cultura e das práticas políticas do Antigo Regime, como a liberalidade régia, as doações em troca de serviços, bases da mercê remuneratória? ${ }^{43}$

Além do mais, as várias guerras vivas de conquista e restauração do Império português faziam não apenas circular os homens, garantindoIhes mobilidade geográfica, mas os levava a ascender na hierarquia social, conferindo-lhes, como ao negro Henrique Dias, as comendas dos Moinhos de Soure, da Ordem de Cristo, além da repartição de algumas fazendas e propriedades em Pernambuco; ao índio temiminó Araribóia (batizado como Martim Afonso), o hábito de cavaleiro da Ordem de Cristo, além de sesmaria e a nomeação de capitão-mór de sua aldeia; a André Vidal de Negreiros, como recompensa dos bons serviços na guerra de restauração de Pernambuco, o governo do Maranhão (1655-56), o de Pernambuco (1657-61), o de Angola (1661-66) e novamente o de Pernambuco (1667); ao reinol (natural da Madeira) João Fernandes Vieira, os cargos de Governador da Paraiba (1655-1658) e de Angola (1658-1661). Vieira, que nunca conseguiu o governo de uma capitania de primeira grandeza, ainda se tornou, em recompensa por seus préstimos à Coroa, membro do Conselho de Guerra em Lisboa e superintendente das fortificações entre Alagoas e Maranhão, além de receber duas comendas da Ordem de Cristo. Naquela época era considerado o maior proprietário do nordeste, senhor de 16 engenhos e muitos currais de gado. Morreu em Olinda, em 1681 (provando ter sido, de acordo com a classificação de Alencastro, não um homem ultramarino, e sim um homem colonial). ${ }^{44}$

Se, por um lado, como afirma Nuno Monteiro, tem-se no Oriente, até 1580, a "tradução exemplar do persistente ethos militar da aristocracia portuguesa", na medida em que "os feitos heróicos na Índia se acrescentavam ou substituiam aos do periodo medieval no imaginário bélico da fidalguia portuguesa", isso se explica porque, de acordo com o autor, o "Estado da Índia, freqüentemente deficitário, vivia da memória dos feitos passados, mas também da possibilidade que abria à acção de novos Gamas, Almeidas e Albuquerques". Se, como o autor prossegue,

"no auge da sensibilidade barroca, nos finais do reinado joanino, (...) o vice-reinado indiano parece ganhar novo alento. Senhores de casas da primeiríssima Grandeza da reino aceitam ir para lá. E é nessa altura que mais se celebram, através de publicações impressas, todos os seus feitos e cometimentos, sistematicamente equiparados aos dos heróis quinhentistas",

é preciso estar atentos para as conjunturas e viragens do Império português. Os anos finais do reinado de D. João $V$ coincidem com uma noção mais clara do início do esgotamento do ouro nas Minas Gerais. Relacionada a isso, não poderíamos entender a importância simbólica - e não real - que passou a assumir na literatura veiculada no Reino, os governos - e os nobres governadores - da Índia? Não seria uma espécie de canto do cisne de uma época de ouro do Estado da Índia, de uma Goa dourada que não voltaria mais? 
45

Cf. MONTEIRO, "Trajetórias sociais e governo das conquistas..., op. cit.

46

FURTAD0, Júnia F. Chica da Silva e o contratador dos diamantes. 0 outro lado do mito. São Paulo: Companhia das Letras, 2003, pp. 61-63.
Se passarmos para o Atlântico Sul no século XVIII, certamente decaem o número e os exemplos de naturais do Brasil, ou de pessoas menos nobres no governo das suas respectivas capitanias. ${ }^{45}$ Mas aquele século - e o chamado período pombalino - nos trazem novos exemplos de ascensão que, apesar de exceções, são surpreendentes. É o caso de Simão Pires Sardinha, filho de Chica da Silva e Manoel Pires Sardinha, recentemente estudado por Júnia Furtado. Mulato, fruto ilegítimo da união entre um senhor e sua escrava, Simão foi pródigo - e aqui não podemos esquecer o patrocínio de João Fernandes de Oliveira, o célebre contratador dos diamantes - em se habilitar à Ordem de Cristo. Uma das testemunhas no processo de gênere, o reverendo Domingos Caldas Barbosa, ao mencionar sua mãe e avó maternas (ambas haviam sido escravas), afirmou viverem todos "igualmente opulentos, e com uma copiosa escravatura, vivendo à luz da nobreza", apesar da cor parda da avó. 0 depoimento de outra testemunha - Baltazar Gonçalves de Carvalho, oficial de jardineiro, que vivera no Brasil durante 50 anos - não era muito diferente. Afirmava viverem "todos com uma excelente reputação e à luz da nobreza, com muita riqueza e fazendo a primeira figura naquele continente, visitados das primeiras pessoas". 46

De fato grande era a elasticidade do conceito de nobreza tecido pelas teias que teceram o Império português! E grande a capacidade de inversão do mesmo Império - e de suas conquistas, ou partes ultramarinas! Exemplo disso é a mácula que pesou sobre o irmão de D. Rodrigo de Souza Coutinho, ou então, a fortuna de que gozou Joana da Silva Guedes de Brito, a qual Nuno Monteiro se refere.

De resto, se "a monarquia portuguesa de Antigo Regime manteve-se até o fim prisioneira dos compromissos assumidos pela dinastia no contexto da guerra da Aclamação de 1640-1668", não se há de esquecer que, apesar da distância, e das devidas proporções, essa guerra e seus compromissos incluiram não só os Grandes do Reino, como também os principais e nobreza da terra das conquistas. As mercês a que fizeram jus comprovamno; assim como comprovam a prevalência da cultura política do Antigo Regime, nos trópicos. 